\title{
0 desenho da cidade histórica enquanto elemento de memória e preservação: o caso de Cachoeira, no Recôncavo Baiano
}

\author{
The design of the historic city as an element \\ of memory and preservation: the case of \\ Cachoeira, in the Recôncavo Baiano
}

Elisângela Queiroz Veiga

Mestranda em Desenho, Cultura e Interatividade, Universidade Estadual de Feira de Santana (UEFS);

Bolsista da Fundação de Amparo à Pesquisa do Estado da Bahia (Fapesb);

Bacharela em Arquitetura e Urbanismo, Universidade Federal de Ouro Preto (UFOP);

Bacharela em Design Gráfico, Universidade Federal da Bahia (UFBA);

Licenciada em Matemática, Universidade Estadual de Feira de Santana (UEFS);

elisveigga@gmail.com
RESUMO:

0 artigo apresentado faz um preâmbulo referente a conceitos de memórias que estão relacionados com os espaços que ocupamos e imprimimos nossas experiências, bem como a importância do reconhecimento da materialidade enquanto suporte para a convalidação da memória coletiva. A forma da cidade, por meio do seu desenho, é tomada como suporte dos registros deixados ao longo do tempo pelos seres humanos, sendo proposta uma reflexão sobre o traçado das aglomerações urbanas e suas implicações. 0 caso específico da cidade de Cachoeira, no Recôncavo Baiano, é abordado como exemplo do desenho característico da maioria das cidades históricas brasileiras, que carecem de um olhar respeitoso para com o seu passado e as demandas atuais. Para tanto, as ferramentas de desenho urbano são pontuadas como alternativas no processo de preservação do patrimônio edificado, considerando as formas de ocupação das cidades ao longo do tempo.

Palavras-chave: desenho; memória; desenho urbano; patrimônio; cidade de Cachoeira no Recôncavo Baiano.

\section{ABSTRACT:}

The article presents makes a preamble referring to concepts of memories that are related to the spaces we occupy and print our experiences, as well as the importance of the recognition of materiality as a support for the convalidation of collective memory. The shape of the city, through its design, is taken as a support for the records left over time by human beings, and a reflection on the layout of urban agglomerations and their implications is proposed. The specific case of the city of Cachoeira, in the Recôncavo Baiano, is approached as an example of the characteristic design of most brazilian historical cities, which lack a respectful look at their past and current demands. For this, the tools of urban design are punctuated as alternatives in the process of preservation of the built heritage, considering the forms of occupation of the cities over time.

Keywords: drawing; memory; urban design; patrimony; city of Cachoeira in the Recôncavo Baiano. 


\title{
1. INTRODUÇÃO
}

A nossa atuação no meio em que vivemos será deixado como legado para as gerações futuras para a conformação das suas memórias, assim como nos foram (e continuam sendo) oferecidos elementos para que consolidemos a nossa percepção histórica em relação ao nosso espaço de vivências. Nesse sentido, Maurice Halbwachs, assevera que:

\begin{abstract}
A história não é todo o passado, mas também não é tudo aquilo que resta do passado. Ou, se o quisermos, ao lado de uma história escrita, há uma história viva que se perpetua ou se renova através do tempo e onde é possível encontrar um grande número dessas correntes antigas que haviam desaparecido somente na aparência (HALBWACHS, 2003, p. 45).
\end{abstract}

Os diversos registros visuais que são produzidos ao longo do tempo, conformam um arcabouço de memórias pertinentes às práticas de um determinado grupo, assim como às paisagens de lugares que se modificaram significativamente, compreendidas nesse elenco a organização dos espaços habitados pelo homem.

De acordo comHalbwachs (2003, p. 92),as imagens espaciais têm uma função na memória coletiva, sobretudo no que diz respeito às marcas que o grupo imprime num determinado lugar, o qual, guarda com seus pares uma relação de identidade particular e restritiva."O lugar ocupado por um grupo não é como um quadro negro sobre o qual escrevemos, depois apagamos os números e figuras". Sendo assim, podemos afirmar que as transformações no espaço habitado, promovidas pelos indivíduos que nele vivem, estão em contínua alimentação simultânea. E cada grupo, encontrará significados próprios, uma vez que:

A memória opera com grande liberdade escolhendo acontecimentos no espaço e no tempo, não arbitrariamente, mas porque se relacionam através de índices comuns. São configurações mais intensas quando sobre elas incide o brilho de um significado coletivo (BOSI, 2003, p. 31).

Com relação às cidades, guardamos os registros visuais que fazem parte da nossa história e que jamais poderão estar dissociados do seu lugar de origem. 0 espaço urbano traz consigo um desenho próprio, com suas formas e volumes, resultantes da ação do homem sobre ele, conforme as necessidades que lhes foram impostas ao longo do tempo. Ainda que essas necessidades não tenham advindo de uma coletividade, seu produto contribuirá para a formação de uma memória coletiva.

Nesse aspecto, podemos endossar a colocação de Maria Elaine Kohlsdorf, ao afirmar que as paisagens têm a particularidade de nos contar histórias, as quais estariam apoiadas sobre as memórias de "entes queridos", nas quais estão contidos os "espaços em que viveram" (KOHLSDORF, 1998, p.28). Sendo assim, nossas memórias relativas ao espaço em que vivemos no mundo, se compõem a partir das nossas impressões, permeadas pelas 
memórias (concretas e subjetivas) que nos são apresentadas por nossos antepassados.

Ao considerarmos as cidades, relativamente antigas, definidas corriqueiramente como históricas, tendemos a imaginar que as mesmas apresentam um caráter mais efetivo quanto aos registros visuais, uma vez que tenham sido cenário de um número considerável de ocorrências das mais diversas origens. No entanto, devemos partir do pressuposto de que todas as cidades são históricas, uma vez que carregam consigo as marcas das ocorrências que os seus indivíduos lhes proporcionaram. Adotamos a expressão "cidade histórica" apenas por uma convenção, para denominar aquelas cidades que já foram objeto de tombamento, no todo ou em parte, por órgãos competentes na salvaguarda do patrimônio edificado.

É salutar que reconheçamos a importância da preservação de patrimônios edificados, enquanto registros formais da transformação espacial de uma cidade. A valorização e comprometimento de uma comunidade para com o seu passado, por meio da preservação do lugar em que vive, é sinônimo de respeito para com sua história e com seus antepassados. Salvaguardar os espaços e edificações de um núcleo urbano, contribui para uma melhor compreensão dos eventos e modos de viver de tempos pretéritos.

Os registros impressos em uma cidade de origens mais remotas são como camadas que se interpõem ao longo do tempo, carregando consigo tantos registros quantos lhe tenham sido favorecidos pelos seus habitantes, e aqueles que possam ter interferido em seus processos de transformação. Podemos reforçar esse posicionamento, ao considerar que:

Na cidade persistem elementos de vários tempos. Edificações e
configurações de seu assentamento primitivo convivem com
elementos de um passado mais próximo e/ou construções
contemporâneas, refletindo a história dos grupos sociais que
sucessivamente geraram esse espaço (LANDIM, 2004, p. 37).

Intervenções que descaracterizem a organização espacial passada de uma cidade, proporcionam uma alteração considerável em sua paisagem, comprometendo a sua memória coletiva, ainda que muitos dos seus indivíduos guardem informações relevantes. Pois, com o passar do tempo, os relatos transmitidos aos demais, sofrem interferências de cunho subjetivo, que não podem ser verificados eficientemente no ambiente que se apresenta no momento.

Em se tratando da preservação do patrimônio, para que os efeitos sejam positivos há que se criar uma relação de pertencimento entre os indivíduos relacionados com os elementos a serem preservados. Um determinado bem, configura a materialidade de uma memória coletiva que encontrará subsídios mais consistentes para se perpetuar, uma vez que os grupos, com o passar do tempo, fragmentam-se no que diz respeito às premissas que outrora os fizeram cúmplices em um mesmo pensamento. 
A cidade encontra lugar de destaque ao materializar diversas manifestações dos seus ocupantes, guardando consigo as marcas das diversas influências a que se submeteram suas gentes. "Cada cidade é um palimpsesto de histórias contadas sobre si mesma, que revelam algo sobre o tempo de sua construção e quais as razões e as sensibilidades que mobilizaram a construção daquela narrativa" (PESAVENTO, 2007, p. 17). 0 espaço urbano, guarda em si, parte substancial do que conhecemos como patrimônio material.

Ao longo dos séculos e das civilizações, sem que aqueles que a construíam ou nela viviam tivessem intenção ou consciência, a cidade desempenhou o papel memorial de monumento: objeto paradoxalmente não elevado a esse fim, e que, como todas as aldeias antigas e todos os estabelecimentos coletivos tradicionais do mundo, possuía, em um grau mais ou menos restrito, o duplo e maravilhoso poder de enraizar seus habitantes no espaço e no tempo (CHOAY, 2006, p. 181).

"Quando um grupo está inserido numa parte do espaço, ele a transforma à sua imagem, ao mesmo tempo em que se sujeita, e se adapta às coisas materiais que a ele resistem" (HALBWACHS, 2003, p. 92). Os bens que se mantém ao longo do tempo, num determinado espaço, corroboram para uma identificação melhor sedimentada dos membros de um grupo, aos quais estejam associados. Com isso, a noção de preservação é melhor apreendida pelos indivíduos, uma vez que se sintam familiarizados e corresponsáveis pelos bens pertencentes ao seu espaço de convívio.

No Brasil, a atenção para com a preservação dos bens que se relacionavam com a cultura e memória, em diversas partes do território, teve lugar, sobretudo, a partir do início do século XX, quando se deu início à criação de instituições que se ocupariam de salvaguardaro que se configurava como patrimônio, determinando os critérios a serem considerados para que adquirissem tal definição.

Com a criação do Instituto do Patrimônio Histórico e Artístico Nacional (IPHAN), em 1937, ainda sob a denominação de Serviço do Patrimônio Histórico e Artístico Nacional (SPHAN), composto em sua maioria por pensadores modernistas, foi estimulado no país o resgate das características próprias da cultura brasileira, na tentativa de afastar-se da influência europeia. Para isso, os membros apoiaram-se no modernismo brasileiro e no resgate das características coloniais das nossas cidades, com a justificativa de comprometimento com a identidade nacional.

O IPHAN iniciou sua atuação na salvaguarda do patrimônio nacional, sendo visto como um órgão autoritário, que se valia do tombamento para impedir a atuação do indivíduo sobre os bens tombados. Ocorre que, para o tombamento encontrar justificativa junto aos seus usuários, haveria de existir, previamente, uma relação de uso e memória das pessoas com os referidos bens, caso contrário, as motivações das ações de preservação estariam fadadas ao fracasso. 
Cabe observar que, ainda que o IPHAN esteja em atuação há mais de 80 anos no país, as ações voltadas à conscientização da comunidade para com a preservação de bens materiais e imateriais, ainda não surtiram os efeitos necessários para um efetivo envolvimento dos indivíduos com os objetos a serem protegidos. Nem mesmo uma compreensão mais aprofundada da importância de tal preservação, e como a mesma pode se dar em consonância com as demandas da população.

Isso se aplica às cidades tombadas, no todo ou em parte, que ainda hoje se configuram como cenários de disputas entre intervenções preservacionistas, em contraponto com as adapatações por uma melhor acessibilidade ou as demandas do mercado imobiliário.

A preocupação em viabilizar uma cidade que atenda às necessidades das pessoas é algo relativamente recente, haja vista a conformação espacial das nossas cidades históricas. Essas, quase sempre estiveram associadas a interesses de ordem econômica, começando pela localização das mesmas. Para ilustrar, podemos citar aquelas que tiveram como incentivo de implantação a condição de entreposto comercial ou a localização de algum recurso a ser explorado. Com isso, a urbe se desenvolvia em torno das atividades econômicas preconizadas pela sua condição mercadológica.

Além de uma localização predeterminada, as cidades foram adotando traçados e formas conforme preceitos ditados pelo poder hegemônico de cada momento histórico, bem como pelas características físicas dos territórios em que se implantavam.

\section{DESENVOLVIMENTO}

\section{1. $O$ traçado das cidades}

Não é possível afirmar com precisão quando o ser humano resolveu fixar-se em um determinado sítio, convivendo coletivamente com seus semelhantes. Por mais que se tenham informações a respeito desse assunto, muito mais se carece para precisar ações dessa natureza. Muito do que nos poderiam contar as antigas cidades, encontra-se enterrado sob as urbes que se reconstruíram sobre seus vestígios originários ao longo do tempo. Outros tantos, se perderam em decorrência da sua vulnerabilidade às ações do tempo, e de natureza antrópica.

No entanto, podemos encontrar subsídios referentes aos primeiros assentamentos, e suas características espaciais, que remontam ao período Neolítico, entre 3.000 e 4.000 anos antes de Cristo, nas imediações dos vales dos rios Tigre e Eufrates. Essas aglomerações indicam a intenção de domínio da natureza e de ordenação da agricultura, sem, no entanto, configurar argumentos sólidos que justifiquem o despontar das aglomerações urbanas.

Ainda que cercada por muitas imprecisões, uma coisa é certa: nenhuma cidade surge por acaso. Segundo Medeiros (2006, p. 176), seja por 
questões referentes à defesa, ao comércio, à garantiada posse do território, ou ainda, em decorrência de algum simbolismo, sempre existirá um fator determinante para a fixação de um grupo num território. E, ao decidir ocupar um espaço, já estará determinando uma espécie de planejamento. "A visão de planejamento não deve se restringir à verificação das características geométricas de uma trama viária, e sim ponderar outros spectos temporais que condicionam os eixos de crescimento e retração em assentamentos urbanos".

O estudo do traçado das cidades, desde muito tempo, tende a associar a ortogonalidade das vias ao aspecto de um suposto planejamento, enquanto a ocupação caracterizada por vias tortuosas, que se adapata ao terreno, atribui-se o caráter de desordem. Na verdade, estaria esse último modelo, condicionado aos aspectos geográficos do sítio, definindo "um sistema de crescimento urbano extremamente flexível, que mais facilmente responde às demandas sociais e funcionais de períodos históricos específicos" (MEDEIROS, 2006, p. 196).

Ao longo da história das cidades, e sua conformação, essas duas características surgem nas mais diversas localizações de tempo e espaço, quando não, associadas num mesmo território. Portanto, é equivocada a ideia de que a malha reticulada, seja um indício de contemporaneidade do ordenamento do solo urbano. As colônias gregas e romanas já apresentavam tal característica, que encontramos ainda nas colônias espanholas da América Latina e em cidades da América do Norte.

A grelha, tão assimilada como elemento ordenador do espaço, teria "dois propósitos simples": contemplar "um simbolismo associado à efetiva tomada intencional da terra" e facilitar "a colonização ao permitir a consolidação de maneira mais rápida e eficaz" (MEDEIROS, 2006, p. 197198). A topografia seria ignorada, facilitando a implantação em qualquel localidade, conforme assegura Reader (2004).

Na dita América Portuguesa, a ocupação do território esteve sempre associada à falta de planejamento dos portugueses, que acreditava-se não disporem de métodos e conhecimento técnico para tal empreendimento. De acordo com Kostof (2001), a cidade com características orgânicas, dificilmente estariam associadas a uma racionalidade de ocupação antes da era moderna.

0 perfil da cidade portuguesa seria uma herança do medievo, primando pela adaptação ao sítio e que era, segundo MEDEIROS (2006, p. 242), "esculpida por ruelas estreitas, praças esconsas e lugares de beleza peculiar". Essa característica, fez com que a cidade portuguesa fosse preterida, em detrimento do suposto planejamento urbano ostentado pelas malhas ortogonais adotadas pelos espanhóis na América Latina, conforme assegura Teixeira (2000).

A maior parte das cidades, implantadas inicialmente no Brasil, estavam localizadas no litoral, ou nas proximidades, facilitando o contato 
com a metrópole. Muito da aparente ocupação espontânea do território estava atrelada a medidas de defesa e proteção, combinando baías e elevações, como nos casos de Salvador e Rio de Janeiro. Com o tempo, a parte referente à cidade baixa, passa a abrigar o comércio nas imediações dos portos.

Conforme assevera Medeiros (2006), as cidades portuguesas, implantadas em conformidade com os acidentes geográficos dos territórios, dispunha seus edifícios conforme a topografia, suas praças se estruturavam lentamente, sendo, como suas vias, definidas pelo relevo. 0 autor enfatiza, ainda, uma particularidade que diferencia os núcleos urbanos portugueses:

\begin{abstract}
ali há quase que sempre a convivência entre os traçados eruditos, articulados, planejados segundo rígidos cânones de estruturação urbana, e aqueles de origem vernacular, compostos a partir de uma apropriação do território cujas intenções são particularizadas e promovem desenhos urbanos tendentes a baixo grau de ordenamento (MEDEIROS, 2006, p. 260).
\end{abstract}

De acordo com Medeiros (2006), o traçado da cidade portuguesa seria uma mescla do formalismo, evidenciado em formas geométricas regulares, planejado previamente por um poder central, e do espaço conformado em partes, atrelado a interesses particulares e privados, aparentando pouca ordem. Essa dualidade, nas cidades do Brasil Colônia, vai se impondo ao longo da consolidação das mesmas, determinando uma característica peculiar das cidades brasileiras, conforme observa Teixeira (2000). Com a interiorização do Brasil, por meio das Bandeiras, vão sendo adotados os traçados mais geométricos.

Os assentamentos urbanos brasileiros se expandem e crescem a partir do século XIX. Com o fim da Guerra do Paraguai, a abolição da escravaturae o êxodo do campo para a cidade, muitas pessoas migram para as cidades maiores, aquelas que configuravam os núcleos iniciais da colônia. Com isso, as malhas urbanas, conformadas por tecidos diversificados, cresceram de forma alarmante, propiciando a segregação espacial, determinando o isalamento de alguns núcleos.

Em grande escala, tanto o modelo ortogonalizado do tecido urbano, quanto aquele caracterizado pela irregularidade, tendem a apresentar problemas. Em "grandes cidades ou capitais, a irregularidade pode se transformar em uma característica excludente da vitalidade urbana ampliandoproblemas de setorização, segregação e exclusão social". Já os tecidos ortogonais, quando visualizados em "grandes assentamentos onde há uma nítida malha regulada, embora não exista uma adequada articulação interpartes, recaímos na questão do labirinto e as aparentes vantagens de uma malha aberta" (MEDEIROS, 2006, p. 271-272).

Quando em menor escala, espaços compostos em tabuleiro, seriam favoráveis a uma maior fluidez, enquanto os tecidos irregulares estariam associados a espaços mais interessantes e aprazíveis. Nesse último caso, 
encontram-se cidades como Cachoeira, Mucugê e Tiradentes, de acordo com Medeiros (2006).

A cidade de Cachoeira apresenta o típico traçado irregular lusitano, estabelecido entre o imponente rio Paraguaçu e as encostas á sua esquerda. Com isso, a cidade que se iniciou à margem do rio, foi adotando maiores cotas para suas edificações, adaptando-se ao terreno e fugindo dos efeitos das enchentes. Com a expansão do seu núcleo, sobretudo no final do século XIX e início do século XX, a porção mais íngreme foi ocupada, principalmente para fins residenciais.

\title{
2.1.1. O Desenho da Cidade de Cachoeira
}

Cachoeira teve considerável relevância no cenário econômico brasileiro durante o período colonial e do império. Localizada na primeira região urbanizada do Brasil, subordinada a Salvador,o Recôncavo Baiano, funcionou como entreposto comercial entre a capital e o interior da porção continental do país. "Por ser ponto de passagem obrigatório do transporte fluvial para o terrestre, durante dois séculos, Cachoeira desempenhou a função de empório de uma rica e vasta região" (PESSOA e PICCINATO, 2007, p. 117).

De acordo com o Programa de Desenvolvimento Integrado da cidade monumento de Cachoeira, Secção II/ Plano Diretor (1976), há que se considerar Cachoeira, como:

\begin{abstract}
Polo de desenvolvimento de singular importância no período colonial, ponto obrigatório de passagem dos produtos que, vindos do exterior, iam a Salvador e da "Cabeça do Brasil" seguiam para Cachoeira, para daí tomar o destino do sertão da Bahia e das Capitanias do Sul e o Centro, desde o século XVIII Cachoeira desempenha destacado papel nesse sentido centrífugo, como também no centrípeto, recebendo os produtos dos mesmos pontos em sentido contrário, para seguirem até Salvador e daí atingirem o mundo português (INSTITUTO DO PATRIMÔNIO HISTÓRICO E ARTÍSTICO NACIONAL/UFBA, 1976, n.p).
\end{abstract}

Ainda de acordo com (INSTITUTO DO PATRIMÔNIO HISTÓRICO E ARTÍSTICO NACIONAL/UFBA, 1976), a cidade teve seu traçado inicial determinado pela ocupação linear,à margem do rio Paraguaçu, tendo nascido entre os riachos Pitanga e Caquende, apresentando um tecido urbano próprio das cidades lusitanas, com pequenas quadras e ruas curvilíneas, compostas por edificações que representavam o posicionamento estratégico da cidade no cenário econômico, inclusive como pólo açucareiro.

Além dos dois riachos que abrigavam o embrião do assentamento urbano de Cachoeira, figurava o imprescindível rio Paraguaçu que equiparava-se em importância, ao rico solo de massapê da região, enquanto fomentador da implantação do povoado. A água desse rio foi de suma importância, tanto para a agricultura (irrigação e funcionamento dos engenhos), quanto para o escoamento da produção e circulação de diversas 
mercadorias. Essa característica nos remete à implantação de cidades da civilização mesopotâmica que se implantavam nas várzeas, no intuito de estabelecer a posse de terras irrigadas.

Uma aproximação da organização espacial da vila, no final do século XVIII, pode ser observada na ilustração "Villa de Cachoeira" (sem datação), (Figura 1). A aquarela, da qual se desconhece a autoria, prima por uma representação objetiva, rica em detalhes. Nela, podemos identificar o traçado da malha urbana e a disposição das edificações mais emblemáticas da cidade, a partir da visada de algum ponto elevado na localidade de São Félix, na outra margem do rio Paraguaçu. As edificações que mais se destacam são os templos religiosos e a Casa de Câmara e Cadeia.

Figura 1:"Mapa da Vila de Cachoeira", sem datação. Autor não identificado.

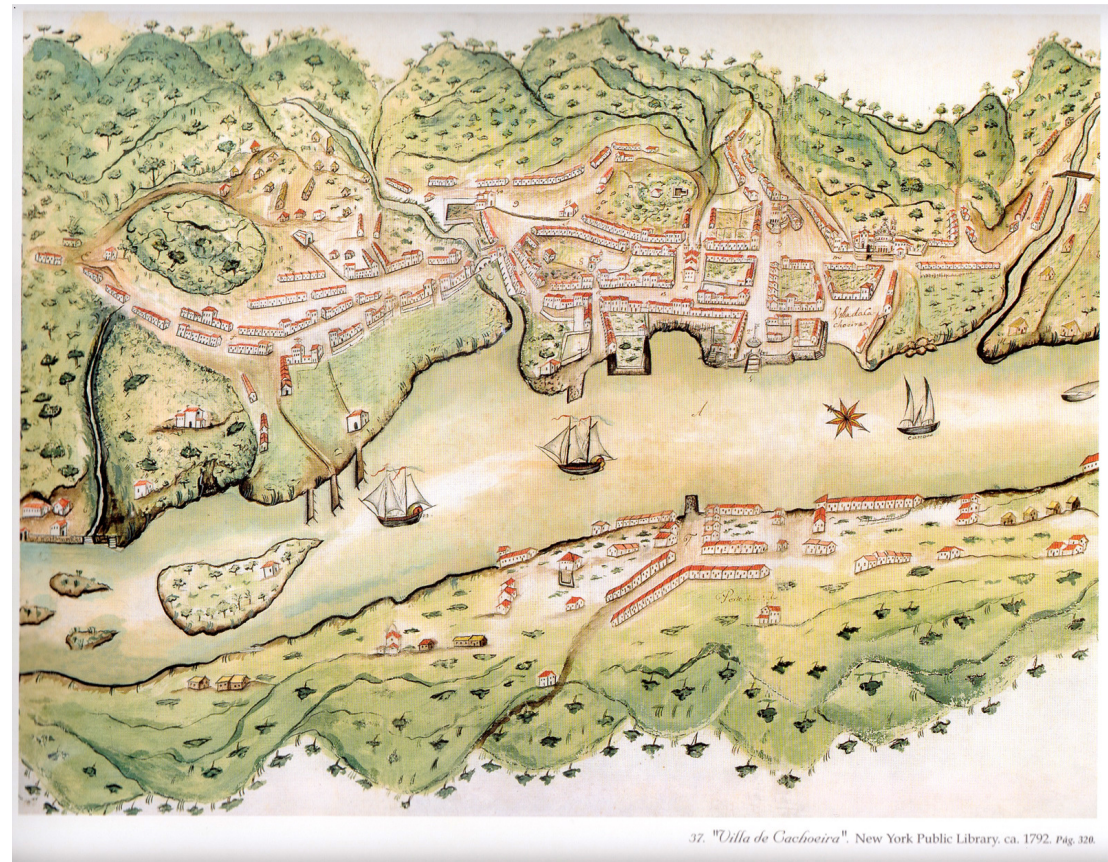

Fonte: Reproduzida em: REIS, Nestor Goulart. Imagens de Vilas e Cidades do Brasil Colonial. São Paulo:Edusp, 2000, p. 55.

A ilustração apresentada define-se pela minúcia que o autor imprimiu ao executá-la. 0 registro deixado se aproxima bastante de como estava organizada a vila quando foi executada a obra. No final do século XVIII "o núcleo urbano já estava plenamente consolidado, com os principais monumentos de arquitetura civil e religiosa já edificados" (PESSÔA e PICCINATO, 2007, p. 118). Com isso, podemos concluir o quão eficiente pode ser um registro visual ao resgatar as características mais marcantes de um território, sobretudo em se tratando de questões voltadas à memória de uma coletividade.

Ao descrever a Villa de Cachoeira, em 1802, Luiz dos Santos Vilhena ressaltou o quão "espaçosa" era, apresentando "bons edificios", dentre os 
quais são elencados a Igreja Matriz e a Casa de Câmara e Cadeia1. Relatou, ainda, a existência de um "bom hospital" e um "convento de Carmelitas calçados", além de uma "passagem para o Arrayal de S. Felix de que annualmente se tira hum bom rendimento para a Camara"2 (VILHENA, 1802, livro II, p. 505).

No início do século XIX, em 1818, antes mesmo da elevação de Cachoeira à condição de cidade 3 , foi executada uma ilustração contemplando, inclusive, a localidade de São Félix, que na época figurava como um bairro de Cachoeira, também com características portuárias. Nessa ilustração, ainda que desprovida de requintes gráficos em sua representação, é possível identificar a relação entre as duas aglomerações urbanas e suas respectivas características edilícias (Figura 2). Trata-se de um registro visual, sob o qual podemos rememorar peculiaridades do espaço urbano, impossíveis de serem contemplados na paisagem atual. E, ainda que muito se tenha modificado ao longo do tempo, a identidade do lugar se mantém pelo reconhecimento da sua singularidade. Algo, de fato, importante, como apregoaria Lynch (1981), de acordo com um dos critérios, definidos por ele, para uma boa forma urbana: o sentido de identidade.

Figura 2: Detalhe da vista do arraial do porto de São Félix, na margem direita do rio Paraguaçu, um dos primeiros adensamentos urbanos da Bahia durante o período colonial. Em: Ponte entre a vila da Cachoeira e a povoação de São Félix. Bahia, 1818. Arquivo Nacional, Fundo Ministério do Reino (BR RJ ANRIO 57.0.MAP.1).

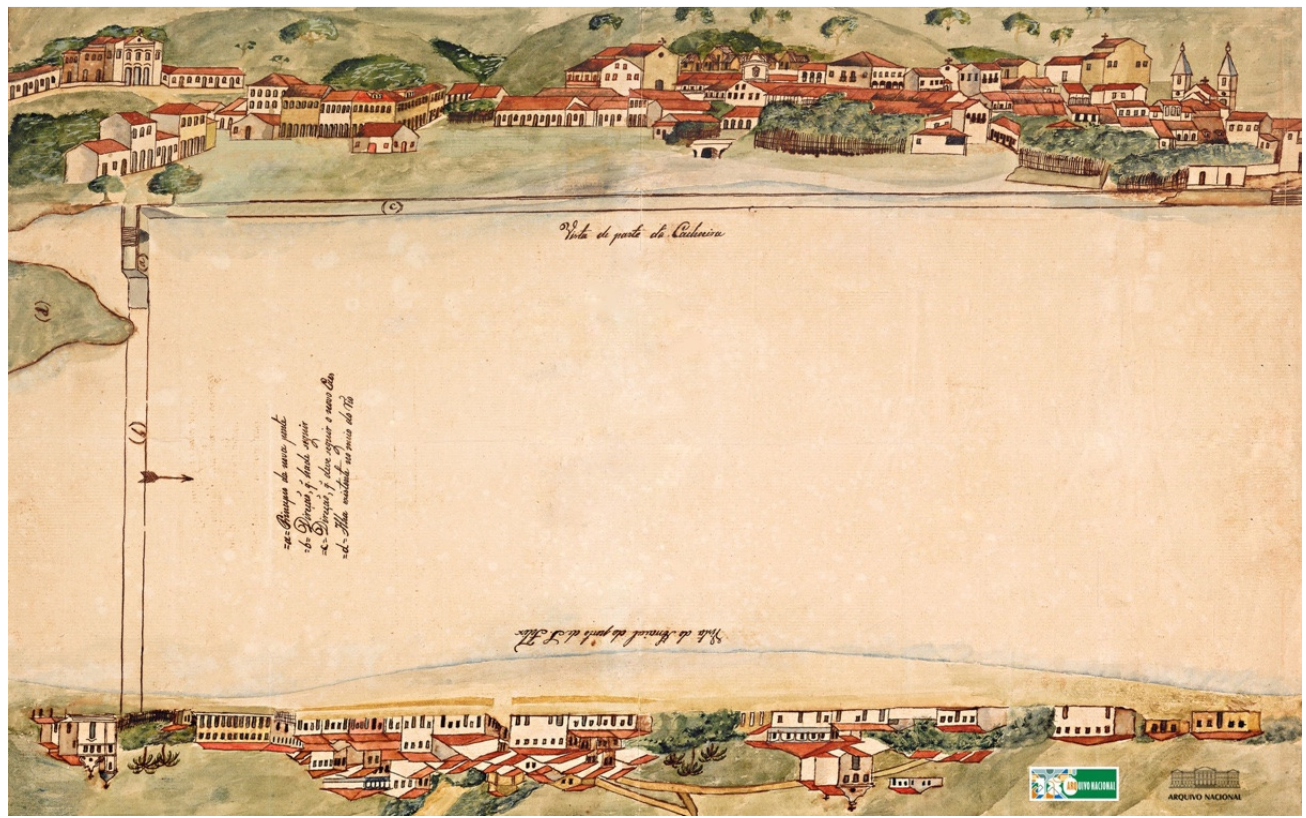

Fonte: http://www.arquivonacional.gov.br/br/difusao/papeis-de-parede/4-papeis-deparede/detail/28-vista-do-arraial-do-porto-de-sao-felix.html. Acesso em: 26 jan. 2019.

1“(...) são igualmente boas, grandes e vistosas as casas do o Conselho em que há espaçozas salas e muito boa cadêa quando as rendas do Conselho não são avantajados" (VILHENA, 1802, livro II, p. 505, grafia original).

${ }^{2}$ Redação e grafia originais.

${ }^{3}$ Cachoeira foi elevada à categoria de cidade em 13 de março de 1837, sob a Lei no 44 . 
Outro registro, não menos importante, nos proporciona a contemplação do frontispício da cidade portuária, no final do século XIX, com suas características edificações de então, bem como as embarcações que aportavam naquela cidade. Algumas particularidades, como o mercado municipal, que foi demolido alguns anos após ser construído, por não ser bem aceito pelos comerciantes de víveres, consta dessa ilustração, à esquerda. (Figura 3).

Figura 3: Parte 1 da ilustração publicada, em agosto de 1868, noThe Illustrated London News, uma revista inglesa ilustrada, que circulou por 161 anos, de 1842 a 2003Cachoeira, Province of Bahia, in the Empire of Brazil.

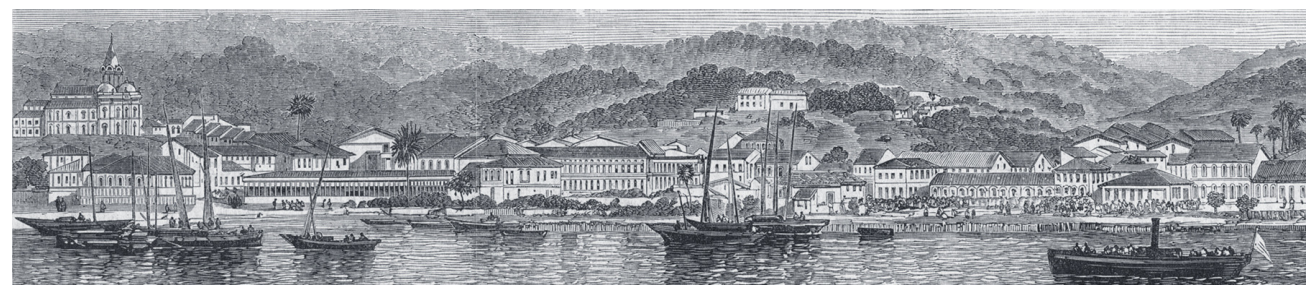

Fonte: http://www.bahia-turismo.com/cachoeira/ilustracao.htm . Acesso em: 28 jan. 2019.

Ainda que mais de um século e meio nos separe do momento do registro apresentado, é perceptível que muitas das características singulares da cidade foram preservadas. Isso se pode concluir devido à possibilidade de reconhecimento de edificações que seguem presentes na paisagem urbana de Cachoeira. Num outro fragmento, da mesma ilustração, podemos identificar o Convento do Carmo (à direita), as torres da Igreja de Nossa Senhora do Rosário (à esquerda) e a atual Praça Teixeira de Freitas (antigo Largo do Pelourinho, no cais) (Figura 4).

Figura 4: Parte 2 da ilustração publicada, em agosto de 1868, noThe Illustrated London News, uma revista inglesa ilustrada, que circulou por 161 anos, de 1842 a 2003Cachoeira, Province of Bahia, in the Empire of Brazil.

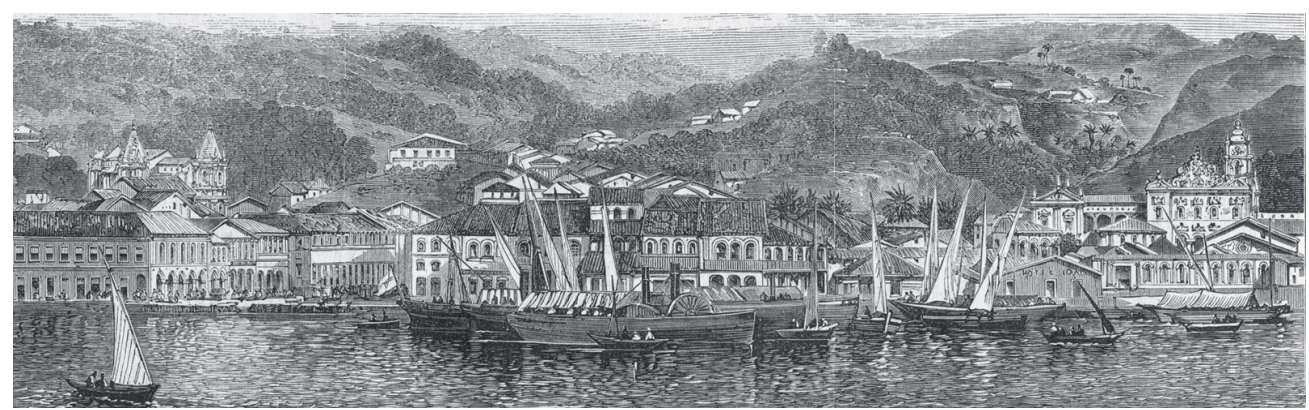

Fonte: http://www.bahia-turismo.com/cachoeira/ilustracao.htm. Acesso em: 28 jan. 2019. 
No século XIX, a área que margeava o rio Paraguaçu desenvolveu-se consideravelmente. Enquanto as edificações voltadas às atividades de armazenamento e transporte de mercadorias situavam-se próximas aos locais de embarque, aquelas de cunho administrativo e residencial foram, cada vez mais, implantadas em zonas de cotas mais altas, resguardando-se assim, dos efeitos das enchentes. Esse teria sido o motivo para a implantação da Casa de Câmara e Cadeia (num "Terrapleno"), bem como a edificação dos Carmelitas, "na encosta do morro da Mangabeira", e da Igreja e Convento da Ordem Terceira do Carmo, em cotas mais elevadas (INSTITUTO DO PATRIMÔNIO HISTÓRICO E ARTÍSTICO NACIONAL/UFBA, 1979, p. 63). Essas características podem ser observadas nas duas últimas ilustrações que, além do patrimônio edificado, evidencia a topografia e vegetação do sítio em questão.

No final do século XIX, após a participação de Cachoeira na Guerra do Paraguai, surgem os primeiros indícios de um declínio sofrido pela cidade. Dentre esses, pode-se listar a redução da população em decorrência da epidemia do cólera (1855), além de informações trazidas por Mello Moraes, em sua obra "Brasil Histórico", no que diz respeito ao meado da década de 1860. Segundo a referida obra, "Cachoeira tinha na ocasião 52 quarteirões contendo 1.051 casas térreas, 233 sobrados e perto de 150 casas de palha". Nessa época as ruas eram "tortuosas e pessimamente calçadas", a iluminação pública "pessimamente servida" (INSTITUTO DO PATRIMÔNIO HISTÓRICO E ARTÍSTICO NACIONAL /UFBA, 1979, p. 104-105). Na Figura 5, podemos observar uma aproximação do desenho apresentado pela malha urbana de Cachoeira em 1880.

Figura 5: Mapa de Cachoeira, 1880.

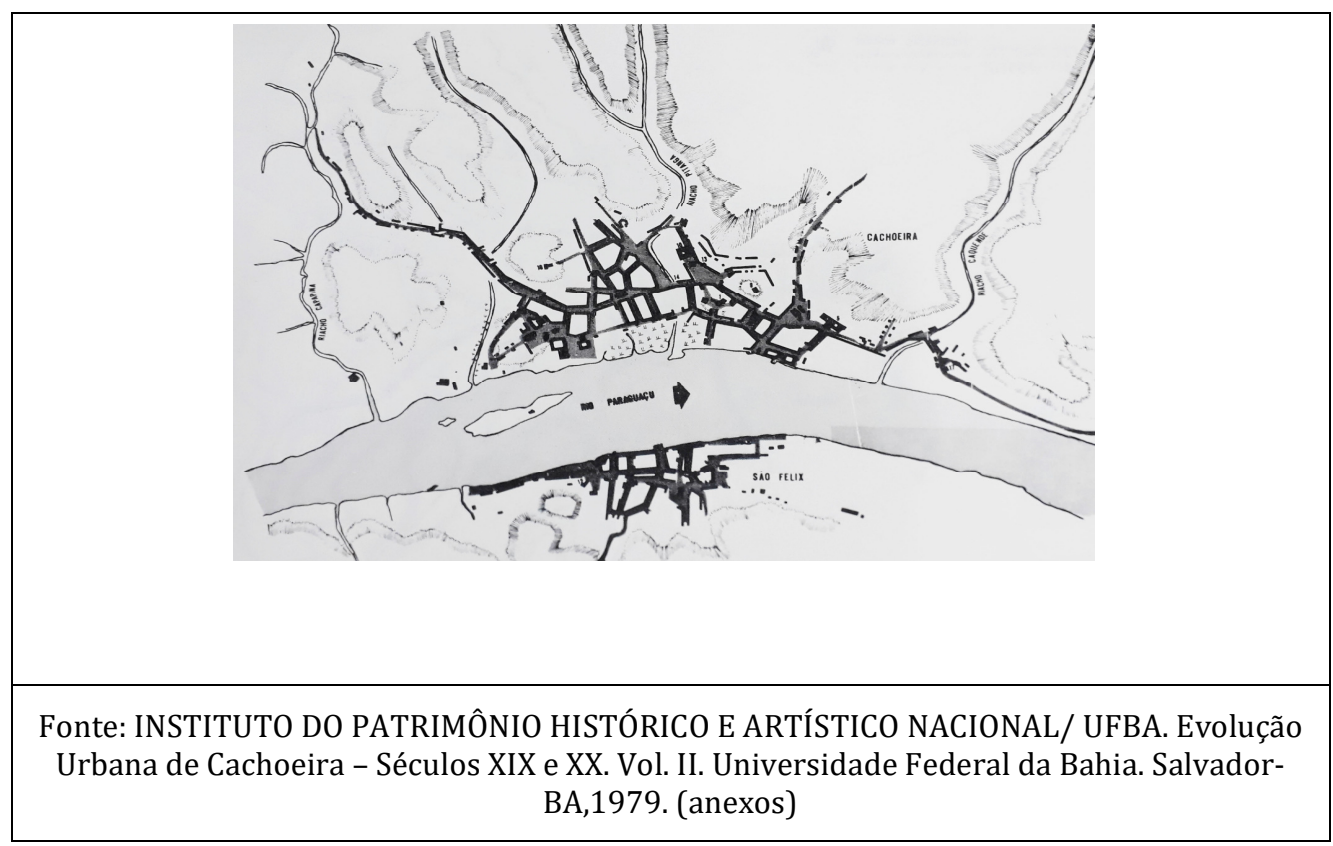


Apesar dos muitos fatores contribuírem para o declínio sofrido por Cachoeira, no final do século XIX, ela "continuava a ser o mais importante entroncamento da Bahia, no concernente ao tráfico de mercadorias" (INSTITUTO DO PATRIMÔNIO HISTÓRICO E ARTÍSTICO NACIONAL/UFBA, 1979, p. 125). Segundo Augusto Mascarenhas, ainda na "segunda década" do século XX, a cidade contava com movimento relacionado às suas atividades associadas ao comércio e o "desenvolvimento da indústria do fumo" (MASCARENHAS, 1979, p. 22apud INSTITUTO DO PATRIMÔNIO HISTÓRICO E ARTÍSTICO NACIONAL/UFBA, 1979, p. 125).

Com o decréscimo das atividades econômicas, devido à queda na produção do açúcar e da exportação do fumo, a partir dos anos de 1950, posteriormente aliadas à implantação da Petrobras no Recôncavo Baiano, Cachoeira entrou num período de estagnação, ao qual esteve associado o seu patrimônio arquitetônico e urbano por longos anos. Esse cenário pode ser observado atualmente, configurado por muitas edificações vazias ou subutilizadas, algumas em estado de ruína, requerendo intervenções urgentes.

O conjunto arquitetônico e paisagístico da cidade foi tombado em 1971, pelo IPHAN, sem, no entanto, ser definido o perímetro a ser protegido. Em 2005, foi lançado edital do Programa Monumenta, do Governo Federal que contemplou intervenções em imóveis (privados) e na orla de Cachoeira que passaram por intervenções que deram um "respiro" ao estado de paralisação no qual se encontrava a cidade. Inclusive, o imóvel que cedeu lugar à Universidade Federal do Recôncavo Baiano naquela cidade, uma antiga fábrica de charutos, foi objeto de intervenção do programa.

Ainda hoje, Cachoeira constitui uma aglomeração mononuclear de tipologia simples, cujo crescimento foi condicionado pelo mesmo eixo linear paralelo ao rio. 0 caráter espontâneo de seu desenvolvimento confere à malha urbana da cidade um desenho irregular resultante de sua paulatina adequação ao próprio sítio. Nos últimos cem anos, essa trama urbana pouco se modificou. As transformações mais importantes são observadas na formação de favelas ao longo de alguns trechos das encostas, mas a variação do número de habitantes no último século também é irrelevante (PESSÔA e PICCINATO, 2007, p. 119).

Muito do traçado da malha urbana da cidade guarda consigo as memórias de atividades desenvolvidas no passado, como no caso da Rua 13 de maio, conhecida antigamente como Rua de Baixo, que até final do século XIX, concentrava as atividades comerciais da cidade. E sobre a referida, é possível perceber, na "irregularidade da trama urbana", que:

há alternância de espaços que se abrem até se transformarem em largos ou se restringem até se tornarem vielas, numa sequência aparentemente ilógica. Nessa rua, pode ser observado o aspecto imponente de algumas casas de dois ou mais andares, além de edificações que conservam, em perfeita harmonia, características arquitetônicas dos séculos XVIII, XIX e XX (PESSÔA e PICCINATO, 2007, p. 121). 
Além das edificações, que guardam muito do passado memorável da cidade, existem pontos que favorecem a apreciação de panoramas na integração da urbeà sua localização geográfica, como o que se mostra a partir da igreja de Nossa Senhora da Conceição do Monte. Outras ruaspreservam as características fundamentais do passado, por fazerem parte do eixo de crescimento principal da cidade, como a antiga rua Formosa, atual Antônio Carlos Magalhães.

A partir da investigação mais detalhada do traçado da cidade e sua evolução ao longo do tempo é possível compreender os fatores que determinaram a forma assumida pela malha urbana que se apresenta (Figura 6), bem como relacionar a influência dos fatores econômicos e sociais nesse processo.

Figura 6: Vista aérea da cidade de Cachoeira, BA.

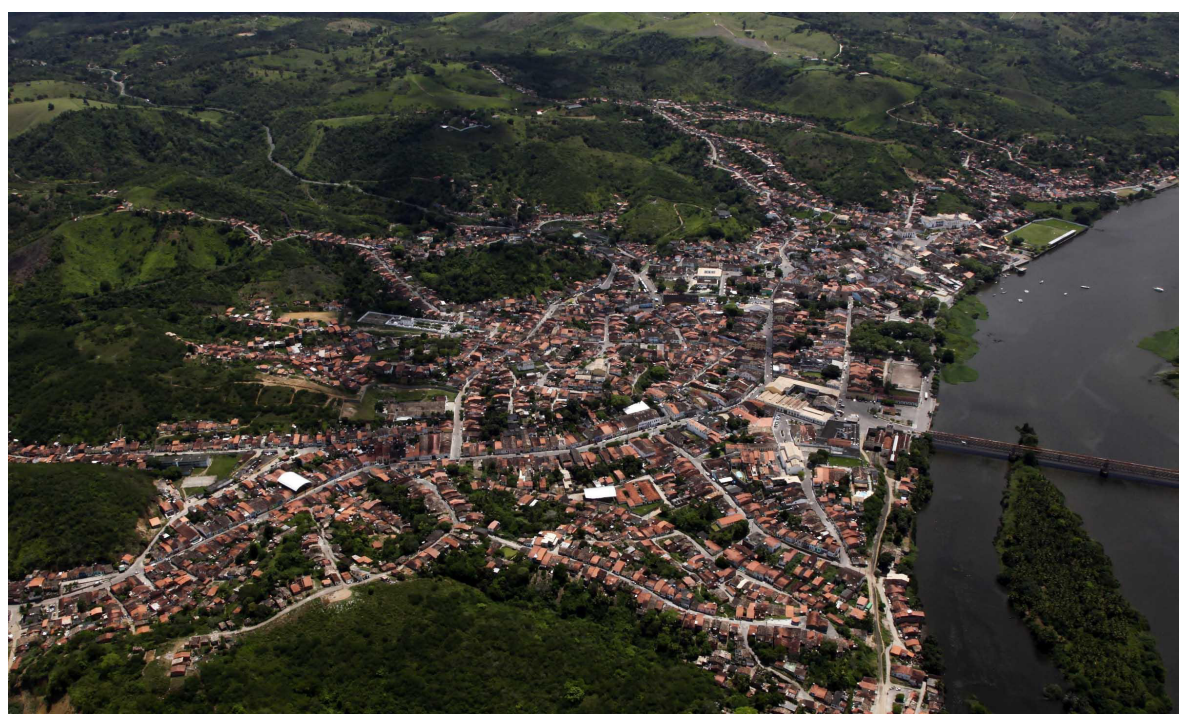

Fonte: Jornal Grande Bahia (http://www.jornalgrandebahia.com.br/2016/10/tem-inicio-asexta-edicao-da-feira-literaria-internacional-de-cachoeira/). Acesso: 12 dez. 2018.

Há que se considerar a importância da preservação das características peculiares que a cidade de Cachoeira ainda guarda no seu conjunto arquitetônico, que se encontra vinculado à memória daqueles que nela habitam. Para tanto, consideremos a importância crucial das ferramentas do desenho urbano como alternativa, não apenas para pequenas cidades, como Cachoeira, mas, fundamentalmente, para os grandes centros urbanos que carregam em seu âmago a história dos nossos antepassados e suas marcas no espaço que habitaram.

\subsection{A cidade histórica e o desenho urbano}

Antes de qualquer abordagem, vale ressaltar o entendimento aqui assumido com relação à expressão "cidade histórica". Para tanto, cabe explicitar que adotamos tal expressão para identificar as aglomerações urbanas, reconhecidamente detentoras de patrimônio edificado, bem como 
de tecido urbano, que apresentam características pertinentes a tempos pretéritos, enquanto arcabouço material da memória coletiva dos povos que com eles intergiram, ou neles se fixaram.

Trata-se apenas de uma convenção adotada, uma vez que a todas as cidades se pode atribuir o caráter histórico, já que, independente do quão distante no tempo se encontre a data de fundação, cada núcleo urbano traz consigo as marcas da atuação dos indivíduos que com as mesmas tenham interagido. No caso específico do Brasil, estaremos nos referindo a cidades que tenham sido tombadas, no todo ou em parte, pelos órgãos aos quais compete a salvaguarda do patrimônio, tanto no aspecto local, quanto internacional.

Ainda que a noção de preservação do patrimônio edificado seja, aparentemente, recente no contexto brasileiro, algumas importantes cidades no mundo, já surgiram com diretrizes de planejamento urbano, em decorrência, muitas das vezes, da importância política e econômica de tais territórios. Para ilustrar essa abordagem, merece destaque a cidade de Washington, capital dos Estados Unidos, inaugurada em 1800, situada às margens do rio Potomac. Verificar esse caso, vale à pena, por se fazer notar a preservação do traçado urbano, estipulado no seu plano inicial (Figuras 07 e 08).

Figura 7 (esquerda): L'Enfant Plan da cidade de Washington em março de 1792. Figura 8 (direita): Vista aérea de Washington (2018).
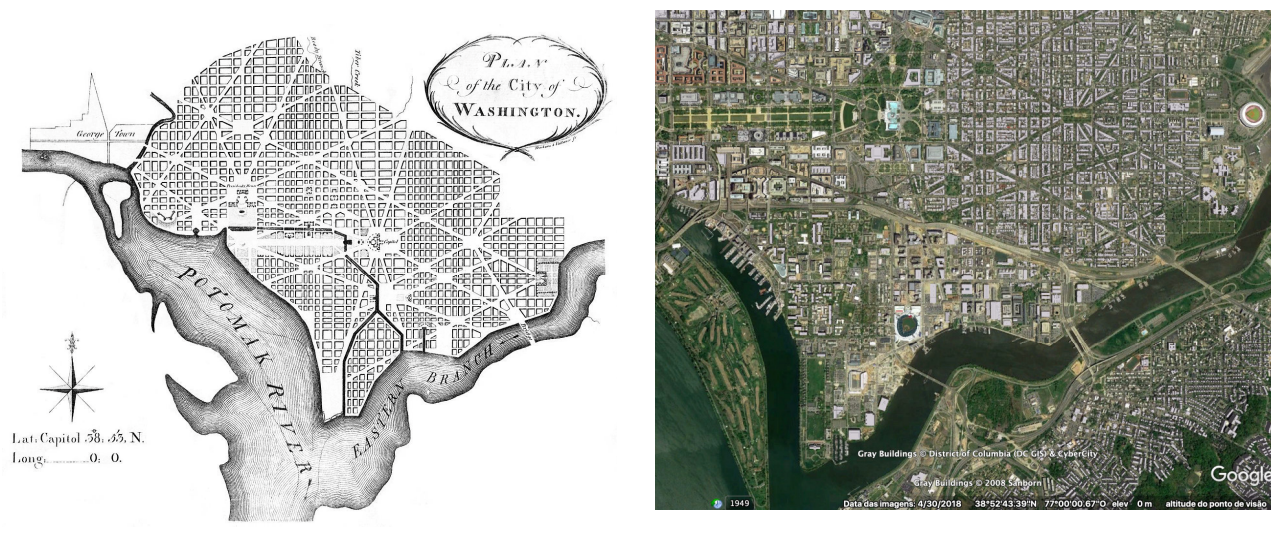

Fonte (Figura 7):https://culturaeviagem.wordpress.com/2013/04/27/como-surgiuwashington-a-capital-planejada-dos-estados-unidos/ Acesso: Dez. 2018. Fonte (Figura 8):Google Earth Acesso: Dez. 2018.

No entanto, cidades surgidas a partir de um planejamento urbano, inclusive no que se refere ao seu traçado, não foi algo comum, assim como não o é, com relação às cidades contemporâneas. Foi,com estímulos iniciais de países como a Inglaterra, que os centros urbanos passaram a gerar interesse no que diz respeito à preservação e interpretação do seu 
patrimônio ambiental, a partir do planejamento interpretativo, segundo Murta e Albano (2002), contribuindo com a indústria do turismo, inclusive.

Juntamente com a reestruturação econômica, países centrais empenharam-se em atender à nova ordenação mundial, apoiando-se na defesa da revalorização dos centros urbanos históricos, implementando atividades terciárias e aquelas de ordem econômica desenvolvidas pelo turismo. NoBrasil, apenas tardiamente, por volta da década de 1990, foram implementados programas de reabilitação urbana e arquitetônica, compreendendo os sítios históricos. Ainda assim, em cidades pontuais.

A obra de Aldo Rossi, entitulada"A arquitetura da cidade", de 1966, contempla um método de interpretar a cidade, atribuído ao arquiteto em questão. Esse foi um dos trabalhos que buscou congregar a arquitetura e o urbanismo, partindo da análise morfológica urbana, visando alcançar um método de projetar, de forma coerente com a cidade histórica. Essa análise, configura-se como um recurso que pode se utilizar de registros visuais, como elementos na preservação da memória.

Em fins da década de 1970 as intervenções urbanas passaram por reformulações na sua metodologia, adotando ajustes criteriosos.

\begin{abstract}
Nesse período, haveria a afirmação do Desenho Urbano como campo específico que enfatizava a percepção da cidade existente, ou seja, as características específicas do contexto urbano preexistente em que se pretende atuar. A preocupação com a escala humana e a cidade vista como cenário das relações humanas passariam a fazer parte dessa nova metodologia (ZANETTI, 2005, p. 16).
\end{abstract}

Muitas críticas foram direcionadas a grandes conjuntos habitacionais que propiciavam uma qualidade ambiental insuficiente, assim como a ação de substituição de partes antigas, baseada em técnicas mais racionais e avançadas na arquitetura. A partir de então, novas metodologias de projeto, considerando a reabilitação urbana, e preservação, foram incorporadas ao exercício do urbanismo, visando a valorização dos centros históricos, reabilitando imóveis e espaços, de forma integrada, como o que começou a ser praticado na Europa.

Segundo Pesavento (2007), é no presente que são pensadas as cidades do passado, a partir da reconstrução dada por meio da "narrativa histórica" ou da memória coletiva ou individual de uma determinada geração. Com isso, pode-se afirmar que a materialização dessas memórias, por meio da preservação do patrimônio edificado, torna a reconstrução de uma época precedente, mais substancial.

A cidade sempre se dá a ver, pela materialidade de sua arquitetura ou pelo traçado de suas ruas, mas também se dá a ler, pela possibilidade de enxergar, nela, o passado de outras cidades, contidas na cidade do presente. Assim, o espaço construído se propõe como uma leitura no tempo, em uma ambivalência de dimensões que se cruzam e se entrelaçam (PESAVENTO, 2007, p. 16). 
Entre os anos de 1960 e 1970 grandes cidades em todo o mundo sofreram alterações que modificaram sua escala, contribuindo para a degradação do patrimônio ambiental e imobiliário urbano. Essa prática serviu de incentivo para os diversos processos de reabilitação de muitas cidades europeias, que visavam evitar a monofuncionalidade nos tecidos urbanos, incentivando a recomposição do ambiente degradado e criação de espaços coletivos, levando em consideração a população local.

Conforme Zanetti (2005) as áreas degradadas ou abandonadas de cidades que já haviam se expandido, passaram a se caracterizar como objeto de atenção, uma vez que nessas cidades houve uma disseminação em seus territórios de bairros e cidades satélites logo após a guerra. Essas cidades primaram ainda pela renovação de algumas áreas degradadas e de estruturas viárias, levando em consideração a produção massificada do espaço. Sendo assim, fez-se necessário considerar o patrimônio arquitetônico, adotando premissas de desenho urbano, o que certamente atenderia aos preceitos de preservação.

Nas cidades históricas brasileiras percebe-se que, com excessão dos grandes centros urbanos, poucas delas sofreram alteração da sua escala, mas nem por isso escaparam da degradação do seu patrimônio. Algumas dessas cidadesapresentam grande parte do seu patrimônio edificado comprometido pela ação implacável do tempo e das intempéries, ainda que exista um esforço por parte do IPHAN para com a proteção desses bens.

O Desenho Urbano emerge como alternativa viável e eficiente, no sentido de orientar a prática da arquitetura para a criação de lugares para as pessoas, respondendo às demandas não atendidas pelo planejamento urbano e pela arquitetura.

Essa opção, leva em consideração a morfologia urbana e as demandas sociais envolvidas na conformação do espaço, concentrando-se em "compreender as complexidades do processo de desenvolvimento urbano e em elaborar possibilidades para intervenções a nível da qualidade físicoambiental". A área de atuação do Desenho Urbanopode ser admitida como "o campo disciplinar que trata a dimensão físico-ambiental da cidade, enquanto conjunto de sistemas físico-espaciais e sistemas de atividades que interagem com a população através de suas vivências, percepções e ações cotidianas" (DEL RIO, 1990, p. 48, 54).

Kevin Lynch se preocupava com a dimensão físico-espacial e temporal, e os consequentes efeitos para as pessoas, individualmente, bem como no seu cotidiano, ao definir o Desenho Urbano como: "a arte de criar possibilidades para o uso, gerenciamento e forma de assentamentos ou de suas partes significantes. Ele lida com padrões no tempo e no espaço, tendo sua justificativa na experiência cotidiana humana destes padrões"(LYNCH, 1981, p.290).

Lamas (1992, p.125) defende o desenho urbano enquanto um instrumento das operações de cunho urbanístico, que se coloca a serviço da 
interligação dos "elementos construídos". 0 autor ressalta que "o desenho urbano não deve ser o desenho dos edifícios ou factos construídos, mas o desenho da 'estrutura', o desenho daquilo que une e relaciona os diferentes elementos morfológicos ou as diferentes partes da cidade". A partir disso, podemos elencar o desenho urbano como uma das ferramentas que atuam na produção da paisagem urbana, fomentando a conexão harmoniosa entre elementos morfológicos e os anseios da sociedade.

O Desenho Urbano é um instrumento que proporciona uma reflexão apurada sobre a vida nas cidades, pois favorece o sentimento de pertencimento e exercício da cidadania ao compreender as relações entre usuários e o espaço por eles utilizado. 0 comprometimento com um eficiente planejamento de vias, espaços públicos e edificações, vai além da concepção morfológica da paisagem, pois viabiliza uma melhor qualidade ambiental nas cidades contemporâneas, proporcionando às pessoas o acesso a recursos básicos para uma convivência efetiva em sociedade.

Sendo assim, podemos afirmar, ainda, que os atributos do desenho urbano podem atender às demandas específicas das cidades históricas, que necessitam um olhar comprometido com o seu passado e as reivindicações da contemporaneidade, sobretudo no que se refere à preservação da memória coletiva.

0 desenhista urbano tem como desafio agregar os agentes envolvidos nas decisões a respeito do espaço urbano e, num processo participativo, conduzir uma conformação espacial que propicie a melhoria da qualidade ambiental, induzindo a apropriação de áreas da cidade pelas pessoas, minimizando impactos causados por ocupações, advindas do crescimento desordenado de determinadas regiões. Essas ocupações costumam ocorrer devido a fatores como: especulação imobiliária, segregação espacial e falta de orientação acertada por parte da administração pública.

Ao se colocar a serviço do bem estar dos usuários dos espaços urbanos, as ferramentas do desenho urbano configura-se como um mecanismo de ação no processo de adequação das cidades históricas à contemporaneidade. Pensar uma cidade histórica, de modo a atender as demandas dos indivíduos, sem deixar de lado a importante missão de preservar o seu patrimônio edificado, é algo que pode ser viabilizado por um planejamento comprometido e pautado em premissas básicas de um bom desenho da cidade.

\section{CONSIDERAÇÕES FINAIS}

Considerar as relações de um grupo com o meio em que está inserido,é um fator preponderante nos processos de entendimento de ações a serem implementadas, sobretudo em cidades históricas, que guardam acervos substanciais de memórias coletivas e individuais. 
Assim como as cidades contemporâneas, os sítios urbanos históricos merecem uma atenção especial acerca da compreensão do seu tecido, e dos diversos fatores que contribuíram para que se conformassem com determinadas particularidades ao longo do tempo. Com isso, a preservação e revitalização desses espaços, devem estar associadas a parâmetros que respeitem a história do lugar e as memórias dos seus habitantes, a fim de que a identidade e paisagem de tais locais sejam respeitadas.

Os registros visuais de espaços urbanos, que se perpetuam no tempo, tais como: ilustrações, mapas e fotografias, funcionam como elementos importantes na preservação da memória coletiva e de ações de intervenção nesses espaços. 0 acesso às características pretéritas de um lugar, possibilita a atuação com respeito ao patrimônio existente, bem como no atendimento das demandas contemporâneas.

No Brasil, são numerosos os casos de patrimônios urbanos que se apresentam em estado precário de conservação, sendo que, aqueles que puderam ser contemplados por programas de restauração, apenas um número reduzido obteve resultado satisfatório em relação às suas necessidades. Esse fato, pode ser considerado como uma característica de países que ainda empregam de forma limitada os recursos de planejamento e desenho urbano, para uma melhor compreensão do tecido da cidade histórica e a valorização do patrimônio nacional.

As ações implementadas na cidade de Cachoeira, por exemplo, objetivaram incentivar o desenvolvimento econômico, além da preservação do seu rico patrimônio. No entanto, na atualidade, percebe-se que muito ainda há que ser feito pela cidade, que tão importante lugar ocupa na história do Brasil e da Bahia. 0 tecido urbano carece de uma análise comprometida com o seu desenho original, bem como muitos dos seus imóveis que se encontram em processo de ruína e subutilização.

A área de conhecimento do Desenho Urbano, surge como uma das ferramentas possíveis de serem utilizadas no processo de preservação do patrimônio urbano. A justificativa residenum melhor entendimento entre o espaço urbano e seu patrimônio edificado, uma vez que os recursos possíveis se apoiam no exercício de criar espaços que contemplem as necessidades das pessoas, inserindo-se nesse arcabouço as questões pertinentes à memória dos indivíduos.

Para tanto, o desenvolvimento das ações intrínsecas ao desenho das cidades, deve gozar de uma compreensão acertada, inicialmente, por aqueles que atuam em caráter técnico, junto às transformações do espaço urbano, de modo a influenciar uma postura comprometida com a coletividade, também por parte dos usuários. 


\section{REFERÊNCIAS BIBLIOGRÁFICAS}

BARNETT, J. An introduction to Urban Design. Nova Iorque: Harper \& Row Publishers, 1982.

BOSI, Ecléa. 0 tempo vivo da memória: ensaios de psicologia social. São Paulo: Ateliê Editorial, 2003.

CHOAY, Françoise. A alegoria do patrimônio. 3. ed. São Paulo: Estação Liberdade: UNESP, 2006.

DEL RIO, Vicente. Introdução ao desenho urbano no processo de planejamento. São Paulo: Pini, 1990.

HALBWACHS, Maurice. A memória coletiva. Tradução: Beatriz Sidou. São Paulo: Centauro Editora, 2003.

INSTITUTO DO PATRIMÔNIO HISTÓRICO E ARTÍSTICO NACIONAL/ UFBA. Evolução urbana de Cachoeira - séculos XIX e XX. Vol. II. Universidade Federal da Bahia. Salvador-BA, outubro de 1979.

INSTITUTO DO PATRIMÔNIO HISTÓRICO E ARTÍSTICO NACIONAL/ UFBA. Programa de Desenvolvimento Integrado da cidade monumento de Cachoeira. Secção I. Universidade Federal da Bahia. Salvador-BA, julho de 1976. Não paginado.

KOHLSDORF, Maria Elaine. Percepção da paisagem e planejamento da identidade. Caderno Paisagem. Paisagens (Rio Claro), n.3, 1998.

KOSTOF, Spiro. The city shaped: urban patterns and meanings through history. Londres: Thames and Hudson, 2001.

LAMAS, José Manuel Ressano Garcia. Morfologia urbana e desenho da cidade. Lisboa: Fundação Calouste Gulbenkian, Junta Nacional de Investigação Científica e Tecnológica, 1992.

LANDIM, Paula da Cruz. Desenho de paisagem urbana: as cidades do interior paulista. São Paulo: Editora da UNESP, 2004.

LYNCH, Kevin. A boa forma da cidade. Lisboa. Edições 70. 1981. 448p.

MASCARENHAS, Augusto da Silveira. 025 de junho: papel da Cachoeira na Guerra da Independência do Brasil. Universidade Federal da Bahia, 1979.

MEDEIROS, Valério Augusto Soares. Urbis brasiliae ou sobre cidades do Brasil: inserindo assentamentos urbanos do país em investigaçõesconfiguracionais comparativas. Tese (Doutorado em Arquitetura e Urbanismo), Universidade de Brasília, Brasília, 2006. Disponível em:http://repositorio.unb.br/handle/10482/1557.Acesso em: 05 fev. 2019.

MURTA, Stela Maris; ALBANO, Celina (orgs). Interpretar o patrimônio: um exercício do olhar. Belo Horizonte, MG: Ed. UFMG, 2002. 
PESAVENTO, Sandra Jatahy. Cidades visíveis, cidades sensíveis, cidades imaginárias. Revista Brasileira de História. São Paulo, v.27, n.53, p. 11-23. 2007.

PESSÔA, José; PICCINATO, Giorgio. Atlas de centros históricos do Brasil. Rio de Janeiro: Casa da Palavra, 2007.

READER, John. Cities. Londres: William Heinemann, 2004.

REIS, Nestor Goulart. Imagens de vilas e cidades do Brasil Colonial. São Paulo:Edusp, 2000.

ROSSI, Aldo. A arquitetura da cidade (1966). 2.ed. São Paulo: Martins Fontes, 2001.

TEIXEIRA, Manoel. Imagens do arquivo virtual da cartografia urbana portuguesa. Lisboa: Centro de Estudos de Urbanismo e Arquitectura, Instituto Superior de Ciência eTecnologia, 2000. CD-ROM.

ZANETTI, Valdir Zonta. Planos e projetos ausentes: desafios e perspectivas da requalificação das áreas centrais de São Paulo. 2005. 400 p. Tese (Doutorado - Área de Concentração: Estruturas Ambientais Urbanas) Faculdade de Arquitetura e Urbanismo. Universidade de São Paulo, São Paulo, 2005.

\section{AGRADECIMENTOS}

Agradeço à Fapesb - Fundação de Amparo à Pesquisa do Estado da Bahia, pelo financiamento da pesquisa relativa ao desenho urbano da cidade de Cachoeira, atrelada à participação no Programa de Pós Graduação, Stricto Senso: Desenho, Cultura e Interatividade, da Universidade Estadual de Feira de Santana. 